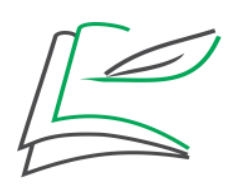

Entretextos

Entretextos 21(1): jan./jun. 2021

ISSN 1519-5392 UEL

DOI: $10.5433 / 1519-5392.2021 v 21$ n1.p.89

\title{
Leitura, oralidade, escrita e gramática: alterações, deslocamentos e permanências nas unidades didáticas dos livros didáticos de Português do Ensino Fundamental II
}

Reading, orality, writing and grammar: alterations, displacements and permanence in the didactic units of Portuguese High School textbooks

\begin{abstract}
Lectura, oralidad, escritura y gramática: cambios, desplazamientos y permanencia en unidades didácticas de libros didácticos de portugués de la enseñanza fundamental II
\end{abstract}

Joceli Cargnelutti* ${ }^{*}$ https://orcid.org/0000-0001-9058-0528

\begin{abstract}
RESUMO: Na tentativa de melhor conhecer a constituição do ensino de língua portuguesa, via livro didático, busco, neste artigo, investigar os objetos de ensino selecionados nas unidades didáticas de coleções de livros didáticos do Ensino Fundamental II, publicados antes e na vigência do PNLD; verificar a ênfase dada a cada objeto de ensino, nas diferentes coleções, bem como pontuar as permanências, as alterações e os deslocamentos ocorridos, nas unidades didáticas, a partir da seleção dos objetos de ensino. Para tanto, a pesquisa se sustenta na perspectiva teórica sócio-histórica, a qual permite compreender a unidade didática a partir de um processo histórico, e o livro didático enquanto um dos instrumentos responsáveis por assegurar a aquisição dos saberes e das competências julgados indispensáveis à inserção das novas gerações na sociedade (Soares 1996). O corpus da pesquisa é constituído por obras didáticas publicadas antes da vigência do PNLD (período das décadas de 1960, 1970 e 1980) e na vigência do Programa (coleções de 1999, 2002, 2005, 2008 e 2011). O que foi possível depreender, a partir dos elementos, é que os livros didáticos são um sinalizador dos processos de permanência, de alteração e de deslocamentos no ensino de língua portuguesa.
\end{abstract}

PALAVRAS-CHAVE: Objetos de ensino. Livro didático. Unidade didática. Ensino de Língua Portuguesa.

ABSTRACT: In attempt to understand better the constitution of Portuguese language teaching via textbooks, I aim, in this paper, to investigate the teaching objects selected in didactic units of elementary school collections published before and during the Programa Nacional do Livro Didático (PNLD - Brazilian Textbook Program), more specifically: verify the emphasis given to each teaching object, in the different collections, as well as point at the permanences, changes and displacements occurred in didactic units, from the selection of the teaching objects. Therefore, this study supports itself in the sociohistorical theoretical perspective, which allows to understand

\footnotetext{
* Professora Doutora em Letras/ Estudos Linguísticos pela Universidade Federal de Santa Maria. E-mail: jocelicargne@gmail.com
} 
the didactic unit from a historical process, and the textbook as one of the instruments responsible for ensuring the acquisition of knowledge and skills considered indispensable for the insertion of new generations in society (Soares, 1996). The research corpus is constituted for didactic works published before the validity of the PNLD (period of the 1960s, 1970s and 1980s) and during its validity (collections 1999, 2002, 2005, 2008 and 2011). What was verified from these elements is the textbooks are a sign of permanence processes, of change and of displacements in Portuguese language teaching.

KEYWORDS: Teaching objects. Textbook. Didactic unit. Portuguese Language Teaching.

RESUMEN: En un intento por comprender mejor la constitución de la enseñanza de lengua portuguesa por intermedio del libro didáctico, este artículo investiga los objetos de enseñanza en las unidades didácticas de colecciones de libros didácticos de la segunda etapa de la enseñanza fundamental, publicados antes y durante el PNLD; verificar el énfasis dado a cada uno de esos objetos en las colecciones, así como señalar permanencia, cambios y desplazamientos entre una y otra unidad didáctica. Para ello, la investigación se basa en la perspectiva teórica socio-histórica, que permite comprender la unidad didáctica desde un proceso histórico y el libro didáctico como uno de los instrumentos responsables por garantizar la adquisición de los saberes y las competencias indispensables en la inserción de las nuevas generaciones en la sociedad (Soares, 1996). El corpus de investigación está compuesto por obras publicadas antes de la entrada en vigor del PNLD (periodo de las décadas de 1960, 1970 y 1980) y durante el desarrollo del Programa (colecciones de 1999, 2002, 2005, 2008 y 2011). Lo que se puede deducir de los elementos analizados es que los libros didácticos son indicadores de los procesos de permanencia, cambio y desplazamiento en la enseñanza de la lengua portuguesa.

PALABRAS CLAVE: Objetos de enseñanza. Libro didáctico. Unidad didáctica. Enseñanza de la Lengua Portuguesa.

\section{Palavras iniciais}

Há algum tempo, venho estudando questões referentes à constituição da disciplina curricular de língua portuguesa via livro didático de português do Ensino Fundamental II. No decorrer das mais variadas leituras, dos mais diferentes autores e obras, fui sendo cativada pela temática livro didático. As pesquisas envolvendo esses manuais procuram lançar sobre esse objeto diferentes olhares: alguns com tons prescritivos, críticos ou de denúncia; outros mais investigativos, conforme Soares (1996). O importante, no entanto, é lançar um olhar diferente, que o investigue, descreva e compreenda, um olhar que se lance do lugar de uma história e de uma sociologia do ensino, o qual busque uma perspectiva sócio-histórica do livro didático.

Também o olhar que normalmente é lançado, para entender esse livro, é sempre à procura do homogêneo, do fio "uno" e claro (BUNZEN, 2005a). Nas palavras de Bunzen, são estudos normalmente avaliativos, que utilizam o livro didático "para fazer uma 'análise do conteúdo' e discutir a maneira com que algum objeto de interesse científico [...] está sendo tratado pelos autores de livros didáticos" (BUNZEN, 2005a, p.558). Ainda não 
se pode esquecer que o livro didático pode ser concebido como um objeto complexo e multifacetado (BATISTA, 1999), inserido num contexto onde há um intenso jogo de forças: políticas, sociais, pedagógicas, econômicas, entre outras. Assim, ele é caracterizado muito mais por uma incompletude e por uma heterogeneidade de saberes, de crenças e de valores sobre a língua e seu ensino/aprendizagem do que num saber-fazer homogêneo e sem conflitos (BUNZEN, 2005b). A noção de complexidade "não deve ser confundida com dificuldade ou complicação [...], trata-se de um posicionamento epistemológico em relação à própria construção do objeto de investigação pelo pesquisador" (BUNZEN, 2005b, p. 17).

Desse modo, na tentativa de melhor conhecer a constituição do ensino de língua portuguesa, proponho-me a, tomando a unidade didática como foco: a) investigar quais são os objetos de ensino selecionados nas unidades didáticas de coleções de livros didáticos do Ensino Fundamental II, publicados antes e na vigência do Programa Nacional do Livro Didático (PNLD); b) verificar a ênfase dada a cada objeto de ensino; c) pontuar as permanências, os deslocamentos e as alterações ocorridas, nas unidades didáticas, a partir da seleção dos objetos de ensino .

Nessa investigação, a unidade didática é entendida como forma de organizar e de apresentar os objetos de ensino no livro didático de Português; os objetos de ensino, por sua vez, são tomados como tudo aquilo que é projetado para o desenvolvimento da competência comunicativa do aluno no que diz respeito à leitura, à escrita, à oralidade e à gramática, bem como se considera o reconhecimento e o uso desses objetos na construção do conhecimento a partir de um processo de sistematização (BENTES, 2010). Entretanto, reconheço que essas conceituações ainda precisam de estudos e pesquisas que definam como esses elementos podem ser entendidos hoje no ensino de língua portuguesa.

Para tanto, a pesquisa se sustenta na perspectiva teórica sócio-histórica, a qual permite compreender a unidade didática a partir de um processo histórico, bem como o livro didático enquanto um dos instrumentos responsáveis para "assegurar a aquisição dos saberes e competências julgados indispensáveis à inserção das novas gerações na sociedade" (SOARES, 1996, p. 116). Também, assim como Bunzen (2005a), defendo uma visão diferenciada, acreditando que o livro didático de Português se caracteriza muito mais por uma incompletude e por uma heterogeneidade de saberes, de crenças e de 
valores sobre a língua e seu ensino/aprendizagem do que um saber-fazer homogêneo e sem conflitos; esses livros são, na sala de aula, "objetos de movimentos de recontextualização e de re-significação, em que as concepções dos professores e dos alunos assumem importantes significados nesse processo" (BUNZEN, 2005a, p.12).

Além disso, o livro didático é tomado, nesse estudo, como um "instrumento pedagógico, uma vez que reflete as várias tradições, inovações e as utopias de uma época" (BUNZEN, 2005a, p. 18). Estudar o livro didático, no Brasil, sob essa perspectiva, é um caminho aberto não só ao conhecimento da constituição da disciplina de Língua Portuguesa, em particular, mas também ao de qualquer outra disciplina, ao longo do tempo, sempre determinado e explicado pela evolução de políticas sociais, culturais e educacionais (SOARES, 1996).

A partir dessa perspectiva e dos objetivos propostos, selecionei o corpus de análise, que é constituído por obras didáticas referentes a dois momentos: antes da vigência do PNLD (período das décadas de 1960, 1970 e 1980) e na vigência do PNLD (coleções de 1999, 2002, 2005, 2008 e 2011). Com a definição das coleções, nem todas completas, foi selecionado um livro de cada conjunto para a descrição e análise, pelo fato de a pesquisa lidar com uma dificuldade inerente a trabalhos que investigam objetos e materiais escolares de outros períodos de tempo, a saber: a não permanência desse objeto na escola. Essa dificuldade acontece porque, conforme Batista (1999, p. 529), esse material é considerado efêmero, pouco digno de catalogação e guarda; por isso, raramente é encontrado nas prateleiras dos acervos públicos, de bibliotecas pessoais ou de instituições, o que dificulta sua aquisição. Desenvolver uma pesquisa envolvendo livros didáticos e, especificamente, a unidade didática e seus objetos de ensino, de certa forma, é lidar com essas limitações e dificuldades.

Assim, as obras escolhidas foram: Português através de textos, de Magda Soares Guimarães, $1^{\text {a }}$ série ginasial (GUIMARÃES, 1960); Comunicação e Expressão, de Roberto Melo Mesquita e Cloder Rivas Martos, $6^{\text {a }}$ série (MESQUITA; MARTOS, 1979); Montagem e Desmontagem de textos, de Hermínio G. Sargentim, $5^{a}$ série (SARGENTIM, 1981); A palavra é sua, de Celso Pedro Luft e Maria Helena Correa, 5a série (LUFT; CORREA, 1996); Português: Linguagens, de William Roberto Cereja e Thereza Cochar Magalhães, $5^{\mathrm{a}}$ série (CEREJA; MAGALHÃES, 1998); Encontro e desencontro em Língua Portuguesa/ Reflexão \& Ação, de Marilda Prates, 5 a série (PRATES, 2005); Português: dialogando com 
textos, de Beatriz Marcondes, Lenira Buscato e Paula Parisi, $5^{a}$ série (MARCONDES; BUSCATO; LAURI, 2006); Língua Portuguesa: linguagem e interação, de Carlos Emílio Faraco, Francisco Marto de Moura e José Hámilton Maruxo Junior, $6^{\circ}$ ano (FARACO; MOURA; MARUXO JUNIOR, 2009).

Para que seja possível apresentar os dados investigados, organizei o artigo em três momentos: no primeiro, a atenção está direcionada para a descrição do conjunto de atividades sequenciadas propostas pelos autores no interior dos livros didáticos que compõem o período das décadas de 1960, 1970 e 1980 (coleções lançadas antes da vigência do PNLD). Nessa parte, os seguintes livros foram descritos: Português através de textos, de Magda Soares Guimarães, Comunicação e Expressão, de Roberto Melo Mesquita e Cloder Rivas Martos e Montagem e Desmontagem de textos, de Hermínio G. Sargentim. Ao analisá-los, busquei compreender como os objetos de ensino, leitura, oralidade, gramática e escrita, inscrevem-se nesses manuais. No segundo momento, descrevo os livros didáticos inscritos no PNLD, publicados a partir de 1990: A palavra é sua, de Celso Pedro Luft e Maria Helena Correa (LUFT; CORREAPNLD, 1996); Português: Linguagens, de William Roberto Cereja e Thereza Cochar Magalhães (CEREJA; MAGALHÃES, 1998); Encontro e desencontro em Língua Portuguesa - Reflexão \& Ação, de Marilda Prates (PRATES, 2005); Português: dialogando com textos, de Beatriz Marcondes, Lenira Buscato e Paula Parisi (MARCONDES; BUSCATO; LAURI, 2006); Língua Portuguesa: linguagem e interação, de Carlos Emílio Faraco, Francisco Marto de Moura e José Hamilton Maruxo Junior (FARACO; MOURA; MARUXO JUNIORPNLD, 2009). O objetivo, ao descrevê-los, é de compreender a ênfase dada a cada objeto de ensino. No terceiro e último momento, dedico à análise dos elementos descritos nos momentos anteriores, procurando pontuar as permanências, os deslocamentos e as alterações ocorridas nas unidades didáticas a partir da seleção dos objetos de ensino. Esse diálogo será guiado pela compreensão/interpretação bakhtiniana, em função de estarmos diante de textos que não são coisas mudas, mas a expressão de, pelo menos, dois sujeitos: o que analisa e o analisado (BAKHTIN, 1997), porque "compreender é cotejar com outros textos e pensar num contexto novo (no meu contexto, no contexto contemporâneo, no contexto futuro)" (BAKHTIN, 1997, p. 404). Por isso, procuro, nessa análise, cotejar as informações descritas nos momentos anteriores, uma vez que "o texto só vive em contato com outro texto (contexto). Somente em seu ponto de contato é que surge a luz que aclara para trás e para frente, fazendo 
que o texto participe de um diálogo" (BAKHTIN, 1997, p. 404). É no contato com outros textos que é construído um novo texto, na tentativa de responder a mais um aspecto direcionado às unidades didáticas e aos seus objetos de ensino.

\section{Antes do PNLD - décadas de 1960, 1970 e 1980}

Ao examinar o livro didático da $1^{\text {a }}$ série ginasial, Português através de Textos, de Magda Soares Guimarães, percebo que a obra está organizada em torno de onze seções maiores, numeradas com algarismos romanos de I a XI, sendo que essas estão subdivididas em vinte e oito seções menores, identificadas por letras minúsculas do alfabeto. As seções retratam uma sequência fixa, composta por texto, gramática e exercícios. Ao ser subdividida em seções menores, cada seção menor também mostra a repetição desse mesmo esquema: texto, gramática e exercícios. Ou seja, esse esquema é apresentado somente uma vez caso a seção maior não tenha subdivisões; quando há subdivisões, essa mesma estrutura é repetida tantas vezes quanto o número de seções menores, marcando assim uma sequencialidade invariável, uma "estrutura rígida" (LAURIA, 2004, p. 165) para apresentação do texto, da gramática e dos exercícios.

Todo o conjunto de atividades proposto, seja nas seções maiores ou menores, mantém a tradição, a qual envolve dois grandes eixos de ensino: texto e gramática; entretanto, é atribuído um tratamento diferenciado a cada um: mais ao texto e menos à gramática. A ênfase dada ao texto já vem marcada no título da obra, que é Português através de textos. No interior das seções, embora cada uma venha intitulada com um tópico gramatical, é apresentada a falsa impressão de que o centro da sequência de atividades é a gramática. Todavia, ao analisar cada seção menor, essa impressão é desfeita. A ênfase ao texto é confirmada no espaço dado ao Estudo do texto, constituído por quatro atividades interligadas, que buscam envolver o aluno no processo de aprendizagem, e no uso de uma mesma fonte gráfica. Para a gramática são reservadas três atividades muito sucintas; além disso, o uso da fonte gráfica é menor.

Intrinsecamente ligado a essa estrutura, está previsto o desenvolvimento de atividades a serviço da seleção dos seguintes objetos de ensino: leitura, oralidade, escrita e gramática, permitindo um trabalho com esses vários objetos. A leitura envolve propriamente a leitura do texto proposto e o estudo do texto, por meio de atividades de interpretação e vocabulário; a escrita é trabalhada com base nas diferentes atividades de 
interpretação, vocabulário, estilo, redação e dos exercícios gramaticais; a gramática é estudada a partir de frases do texto, explicada pela apresentação de exemplos didaticamente organizados e fixada com alguns poucos exercícios; como a oralidade não é trabalhada, entendo que não se constitua um objeto de ensino nessa obra.

Ainda que esses objetos de ensino estejam previstos na sequência de atividades, a ênfase atribuída, a cada um deles, não é a mesma. É perceptível que existe reservado à escrita o maior espaço, fato que se revela pelo número expressivo de atividades previstas na parte do Estudo do Texto e da Gramática. A gramática ocupa um lugar de pouco destaque, embora esteja presente para marcar o espaço da tradição. As atividades de leitura ocupam um lugar restrito, e, para a oralidade, não há um lugar reservado.

O que se nota, a partir de tais dados, é que há uma forma específica de estruturação/organização dessa sequência de atividades a qual, de certa forma, repercute no todo das unidades didáticas, que se traduz em uma sistemática invariável de seções para a apresentação dos objetos de ensino, mantendo uma rigidez, uma sequencialidade, do início ao fim, ou seja, olhar uma unidade didática compreende olhar todas. Além disso, essa forma que trabalha com atividades e exercícios para o desenvolvimento de habilidades e "não se desenvolve, como o ensino de Matemática ou mesmo de conteúdos gramaticais, por meio da exposição de uma 'matéria 'ou de um conjunto de princípios" (BATISTA, 2009, p. 53), reflete, predominantemente, um caráter procedimental.

De certa forma, o livro didático Português através de textos colocava-se na contramão em relação a outras obras que circulavam no período, justamente por centrar sua sequência de atividades no trabalho com o texto e não na gramática. A disposição desse manual revela uma estrutura organizacional rígida, sistemática e invariável, centrada no estudo do texto, confirmando o que a autora sinaliza no título da obra: estudar Português através de textos e priorizando o texto como eixo, enquanto instrumento de ensino.

Já o livro da $6^{a}$ série do Primeiro Grau, Comunicação e Expressão, Mesquita e Martos (1979), é uma obra composta por doze unidades, sendo que cada uma é constituída por três lições, com exceção da última, a qual apresenta apenas uma lição. Ao todo, 34 lições compõem o manual. No índice geral, os autores antecipam poucos aspectos que serão trabalhados no decorrer das lições, restritos a nome e a autor do texto, elementos de reflexão sobre a língua (advindos da gramática tradicional, da Teoria da Comunicação). Desse modo, os pontos privilegiados, no índice, dizem respeito aos eixos tradicionais 
do ensino de língua materna: texto e gramática.

Ao olharmos para os elementos que constituem as lições, a impressão é de que todas apresentam os mesmos elementos; contudo, algumas atividades são constantes (fixas nas três lições), outras frequentes (aparecem em duas lições), outras eventuais (aparecem em uma lição): Texto, Estudo do Texto, Conhecendo Palavras e Conhecimentos linguísticos marcam presença constante, o que evidencia que texto e gramática continuam sendo os eixos das lições e unidades; as atividades Comunicação, Família das palavras, Linguagem oral: ouvir e falar são frequentes, estão presentes em duas lições; observando a linguagem, Técnica de redação, Criatividade, Aprendendo a pensar, Escrevendo corretamente, Pesquisa são atividades eventuais, já que são mencionadas somente em uma lição de cada unidade.

De forma geral, ao se olhar para as lições, sempre é encontrada uma parte fixa (Estudo do texto e Conhecimentos linguísticos) e uma parte variável/flexível de atividades, que se alternam (Família das palavras, Observando a linguagem, Técnica de redação, Criatividade, Aprendendo a pensar, Comunicação, Linguagem oral: ouvir e falar, Pesquisa). Entretanto, ao se observar as unidades, conforme projetadas pelos autores, há a manutenção de uma regularidade, ou seja, a primeira lição de cada unidade apresenta, geralmente, as mesmas atividades; da mesma forma, ocorre com a segunda e a terceira lições de cada unidade. Logo, a regularidade está entre as unidades, não entre as lições. Essa forma de estruturação gera um questionamento: Por que o autor agrupa três lições e denomina esse conjunto com o termo unidade? Uma resposta possível seria que a ideia de unidade, de acabamento, não se dá nas lições individualmente, pois, em cada uma delas, não é trabalhado com todos os objetos de ensino (leitura, escrita, oralidade e gramática); ao contrário, são privilegiados sempre os da tradição (leitura/texto e gramática) e mais um ou outro. A outra lição fica estruturada da mesma forma: objetos da tradição e mais um outro objeto. Apenas a unidade como um todo apresenta essa ideia de trabalhar todos os objetos de ensino requeridos no ensino de Língua Portuguesa na escola.

Na composição das lições, cada uma delas não é exatamente estruturada como a outra, no interior de uma mesma unidade, elas mantêm a tradição envolvendo texto e gramática; porém, é atribuído um tratamento diferenciado a cada elemento: mais atenção à gramática e menos ao texto. Ainda que o título do livro didático, Comunicação e 
expressão, demonstre uma preocupação dos autores de estarem sintonizados com os estudos linguísticos da época, principalmente com a Teoria da Comunicação, não é o que se confirma no interior das lições: Há sim um espaço para esses estudos, marcados pela presença de exercícios envolvendo o estudo do texto, criatividade, linguagem oral; entretanto, são atividades em número menor se comparadas às atividades gramaticais. A ênfase dada à gramática se comprova em função do elevado número de exercícios estruturais, cuja necessidade é treinar o aluno para que ele atinja os níveis cultos da língua portuguesa, sem dispensar o ensino da língua com base na gramática normativa. Além disso, quando ocorre a exclusão/alternância de uma atividade, é sempre referente ao texto, nunca à gramática.

Em decorrência disso, é possível considerar os objetos de ensino a partir desses dois elementos da tradição, texto e gramática: leitura, envolvendo a leitura do texto, as atividades de estudo do texto, família das palavras/observando a linguagem, aprendendo a pensar; oralidade, com o trabalho de linguagem oral e comunicação; escrita, por meio das atividades de criatividade, pesquisa, escrevendo corretamente; gramática, desenvolvida por intermédio dos exercícios de conhecimentos linguísticos. Conforme já comentado, a gramática ocupa um lugar de destaque nas unidades, marcando a posição da tradição; a leitura, embora ocupe uma posição secundária, apresenta um espaço reservado, nas unidades, através do Estudo do texto; a oralidade, por sua vez, ocupa um espaço menos privilegiado, mas há atividades específicas para o desenvolvimento desse objeto de ensino. A escrita, por sua vez, ocupa também um lugar menos privilegiado, sendo explorada, principalmente, na atividade denominada Criatividade.

Na coleção de Hermínio Geraldo Sargentim, o livro didático Montagem e desmontagem de textos, $5^{a}$ série, está estruturado em cinco unidades, cada uma composta por sequências fixas de atividades associadas ao trabalho com o texto. Dessa forma, cada unidade tem o número de sequências de atividades dependendo do número de textos selecionados para serem trabalhados: primeira e segunda unidades, com duas sequências de atividades cada uma; terceira e quarta unidades, com quatro sequências de atividades cada uma; quinta unidade, com três sequências de atividades. Ao todo, 15 textos compõem o manual. As unidades preservam o trabalho envolvendo os dois grandes eixos de ensino de português: texto e gramática; porém, ao texto, é reservado um espaço maior, justamente por ocupar um papel desencadeador de tudo que se projeta em termos das 
atividades. Além disso, ele é centralizador: o trabalho se inicia por ele e os objetos de ensino são trabalhados a partir dele. As etapas previstas para o trabalho com o texto 1 são praticamente as mesmas para o texto 2 .

A ênfase dada ao texto já vem marcada no título da obra, Montagem e Desmontagem de textos. No interior das unidades, as ações previstas, no título da obra, compõem os dois grandes elementos que sustentam as atividades: Desmontagem do texto proposto, envolvendo tarefas com a personagem/narrador, o que faz, sente e pensa a personagem, resumo e estilo; e Montagem de textos, com o estudo de tópicos gramaticais para auxiliar na criação de textos. Isso é ilustrado pela releitura da redação e pelo trabaIho com a ortografia, confirmando a intenção do autor de centrar o estudo no texto. Ademais, as atividades envolvendo o texto são a maioria, ou seja, todas as atividades da Desmontagem do texto e duas da Montagem de textos (criação de textos e releitura da redação) estão, especificamente, ligadas ao trabalho com o texto. À gramática são destinadas duas atividades: tópico gramatical e ortografia.

Recebendo o texto tal importância, os objetos de ensino selecionados, a saber: leitura, escrita e gramática, são trabalhados a partir de atividades que priorizam o trabaIho com o texto. A leitura envolve, propriamente, a leitura do texto proposto e o desenvolvimento das tarefas da Desmontagem do texto (personagem/narrador, o que faz, pensa e sente a personagem); a escrita é trabalhada com base nas múltiplas atividades da Desmontagem do texto e Montagem de textos; a gramática é estudada a partir de tópicos gramaticais, com seus respectivos conceitos, exemplos e exercícios, e da ortografia, também com seus exercícios.

Dentre esses objetos de ensino, o acento maior recai sobre a escrita, tanto nas atividades envolvendo a Desmontagem do texto (que fazem uso da escrita) quanto nas de Montagem de textos (que levam o aluno a produzir texto), pois, a todo o momento, 0 aluno é levado a escrever, registrar, copiar, reescrever, entre outras atividades. Ainda, na atividade de Criação de textos, há uma série de exercícios orientados, direcionando à escrita do aluno; do mesmo modo, ao final da produção do texto, o aluno deve utilizar a ficha de autoavaliação para atribuir um conceito ao texto produzido. Ocupando a escrita um lugar central nos textos, às demais atividades é reservado um lugar secundário, mas relevante. A gramática tem um espaço considerável, em virtude de apresentar um número relativamente grande de exercícios envolvendo aspectos gramaticais. A leitura, por 
sua vez, igualmente, mantém um lugar de destaque, não só pela leitura do texto proposto, mas também pela possibilidade de leitura dos textos produzidos pelos colegas. Para a oralidade, não há um espaço reservado, como também não há o registro de atividades que sinalizam para o trabalho com aspectos orais.

A partir da análise realizada nos três livros didáticos selecionados, publicados antes do PNLD, é possível entender que há uma estrutura mínima comum, marcada por dois eixos centrais que sustentam o conjunto de atividades, dando continuidade a uma tradição do ensino de língua portuguesa: texto, com os exercícios sobre o texto; gramática, com os exercícios gramaticais. Todas iniciam com um texto e, a partir desse, desenvolvem-se as atividades de acordo com os objetos de ensino selecionados.

Embora ocorra certa semelhança, na estruturação das unidades dos distintos manuais, essas não são idênticas em função das seleções/escolhas realizadas por cada autor. Os objetos de ensino selecionados são quase os mesmos, a saber: leitura, oralidade, gramática e escrita, porém acabam refratando de forma diferente no interior das unidades didáticas.

\section{Na vigência do PNLD: coleções de 1999, 2002, 2005, 2008 e 2011}

Ao abrir o manual A palavra é sua, de Celso Pedro Luft e Maria Helena Correa, é encontrada uma obra estruturada em doze capítulos temáticos numerados. Já no sumário, podem ser encontrados os elementos que serão trabalhados no decorrer dos capítulos, de forma que cada capítulo corresponde a uma sequência fixa de atividades, as quais são assim divididas: abertura, texto, interpretação do texto, atividade oral, a palavra no contexto, a palavra no dicionário, leitura suplementar, sala de redação, gramática e treino ortográfico; a partir da sequência de atividades previstas, é possível verificar, no interior de cada uma delas, a presença dos quatro objetos de ensino: leitura, oralidade, gramática e escrita.

Integrados a essa organização, estão os capítulos ordenados a partir de uma organização mínima: texto e gramática, sempre desenvolvidos a partir de uma progressão de atividades e de exercícios. As pequenas alterações de atividades no interior dos capítulos não interferem na estrutura do todo: é o caso, por exemplo, das atividades Palavra no dicionário e Treino ortográfico, deixadas de lado em alguns momentos. A partir dessa organização mínima, são desenvolvidas as atividades dirigidas ao trabalho com os objetos 
de ensino selecionados: leitura, através da leitura do Texto, Interpretação Textual, Leitura Suplementar e Palavra no contexto; oralidade, com o trabalho envolvendo os três momentos com o oral: na abertura do capítulo, antes e após a leitura suplementar; escrita, por meio das atividades de interpretação textual, A Palavra no Contexto, A Palavra no Dicionário e, principalmente, a Sala de Redação; gramática, desenvolvida por meio dos exercícios gramaticais e da parte denominada Treinamento Ortográfico.

Esses objetos de ensino recebem diferentes ênfases no interior da obra: o destaque dado à leitura é grande, em virtude do expressivo número de textos inseridos nas atividades para auxiliar no desenvolvimento dos exercícios e, principalmente, também, por haver, dentro do capítulo, um espaço reservado para a leitura complementar com suas respectivas tarefas. A oralidade aparece como objeto secundário, porém fortemente presente em três momentos no capítulo, com uma diversificação de atividades (dramatizações, jograis, poemas, teatro, narrativas, etc.), entendidas, por mim, como forma de estimular o aluno a expressar opiniões e vivências pessoais a partir da temática proposta em cada capítulo.

A gramática, por sua vez, ocupa um lugar secundário no capítulo; conforme pontuado pelos autores no texto de apresentação ao professor, "o professor não precisa se preocupar em dar tudo. Sugerimos que selecione os tópicos que considere mais importantes (LUFT; CORREA, 1996, p. 1). Além disso, na visão dos autores, "o ideal seria banir quase completamente a gramática do primeiro grau" (LUFT; CORREA, 1996, p. 1). Apesar das posições dos autores, há um espaço reservado para esse objeto de ensino no interior dos capítulos. Já a escrita, ocupa um lugar periférico, já que é desenvolvida, em específico, em uma atividade: Sala de Redação.

O que se pode depreender, então, é que há, de fato, uma preocupação dos autores com o trabalho envolvendo mais o texto e menos a gramática; além disso, o próprio título da obra, A palavra é sua, sinaliza que o enfoque recai num processo interlocutivo, em funcionamento, conforme prevê o uso do pronome "sua", em A palavra é sua, empregada por um locutor em direção a um interlocutor.

Os autores William Roberto Cereja e Thereza Cochar Magalhães organizaram o manual Português: Linguagens, $5^{a}$ série, em quatro grandes unidades temáticas (Comunicação, No caminho da fantasia, Crianças... e Descobrindo quem sou), cada uma dividida em três capítulos. Tais capítulos, por sua vez, apresentam, de forma fixa e invariável, um 
conjunto de cinco atividades, a saber: Estudo do Texto, Produção de Texto, Para escrever certo, A Língua em Foco e Divirta-Se. Essas são subdivididas em atividades menores, as quais variam, frequentemente, em número e em designação, de um capítulo para outro. Assim, a estrutura organizacional da unidade temática é composta por três capítulos, cada um dos quais parte também de uma organização mínima: texto e gramática, e a essa organização são incluídas uma mesma sequência de atividades, voltadas ao atendimento de determinados objetos de ensino: leitura, oralidade, gramática e escrita. Há uma estrutura didática para a apresentação dos objetos de ensino, configurados em um projeto de aula para o ensino de língua portuguesa: a sequência de texto/gramática/exercícios torna-se a sequência projetada da aula por apresentar uma ordem fixa e muito detalhada das atividades. $\mathrm{O}$ trabalho sequencial desenvolvido, em um capítulo, é repetido nos outros dois.

Tomando os objetos de ensino trabalhados, em cada capítulo da unidade temática, é perceptível que há um trabalho envolvendo esses objetos, assim compreendidos nessa descrição: a leitura envolve a leitura do texto inicial e dos demais gêneros textuais do capítulo, bem como o estudo do texto e divirta-se; a oralidade, embora não ocorra uma atividade específica para ela, é desenvolvida com base em atividades de narração, dramatização e apresentação de teatro; a gramática é enfocada nas atividades de Para escrever certo e a Língua em foco; a escrita perpassa todas as atividades, principalmente a produção de texto. Dentre os objetos de ensino, a ênfase recai sobre o trabalho com a escrita pelo expressivo número de atividades apresentadas envolvendo o ato de escrever, seja no estudo do texto, seja nas atividades voltadas à língua; além disso, a escrita está sempre vinculada aos gêneros explorados, instigando o aluno a produzir novos textos a partir das exemplificações esboçadas nos capítulos.

Ocupando a escrita um lugar central, aos demais objetos de ensino é reservado um lugar secundário: a leitura tem um espaço considerável, percebida pela diversidade de textos unidos pela temática de cada unidade, bem como por alguns espaços reservados, especificamente, à leitura no estudo do texto, como ler é diversão, ler é um desafio. A gramática, ainda que não tenha um peso tão grande, possui lugar determinado, uma vez que é trabalhada, de certa forma, em duas atividades: Para escrever certo e a Língua em foco. Por fim, diferente dos demais objetos de ensino, a oralidade é pouco explorada, aparecendo em atividades eventuais de leitura expressiva do texto ou em algumas poucas 
atividades de dramatização, narração e teatro, o que nos leva a questionar sobre a existência desse objeto de ensino nesse livro.

O livro didático Encontro e reencontro em Língua Portuguesa: Reflexão \& Ação, $5^{a}$ série, Prates (2005), é projetado a partir de doze unidades temáticas às quais se vinculam uma variedade de textos, que são explorados por meio do estudo de diferentes gêneros textuais: fábulas, lendas, parlendas, poemas, cartas, bilhetes, música, narrativas, notícias jornalísticas, etc. É possível perceber que há um modo específico de estruturação das unidades, o qual, de certa forma, repercute no todo das unidades, que se traduz numa sistemática de apresentação dos objetos de ensino. Essa forma de organização demonstra que as atividades de ler, escrever, falar e ouvir fazem parte também de uma visão procedimental do ensino de língua portuguesa (BATISTA, 1999), em que cada uma delas ocupa um lugar nas unidades de acordo com as escolhas da autora. A unidade continua a apresentar uma configuração didática, na qual professor e aluno reconheçam os objetos de ensino selecionados.

A partir da leitura da estrutura da unidade, é possível notar que os objetos de ensino são selecionados/priorizados e se desenvolvem por intermédio de atividades que têm, como base, o texto e a gramática: leitura, com atividades de leitura dos textos, por meio de A força da palavra, Estrutura dos textos: conhecer e usar, Visão crítica: fala leitura e escrita e Ampliando horizontes; oralidade, com o trabalho envolvendo A palavra escrita e falada; escrita, baseando-se na Produção de texto e nas demais atividades que incluem a escrita; gramática, desenvolvida por intermédio da Linguagem: análise, reflexão e uso.

Esses objetos de ensino recebem uma determinada ênfase pela autora: a ênfase dada à leitura se traduz com base no grande número de textos disponibilizados ao aluno e pelas atividades que abarcam a exploração dos textos; além disso, a todo o momento, o aluno está sendo convidado a ler, reler, ler o que o colega produzir, ler expressivamente, etc. A gramática, embora ocupe um lugar secundário, nesse manual, é abordada sistematicamente em todas as unidades. Desse modo, é possível perceber a preocupação da autora em proporcionar a construção dos conhecimentos gramaticais a partir de exemplos e de comparações, bem como a preocupação dela em fazer permear os elementos gramaticais nas diferentes atividades, não ficando restritos apenas a uma atividade. A escrita, por sua vez, também ocupa um lugar secundário, sendo dedicado, a ela, um espaço 
específico para a produção escrita, ocorrendo, de forma regular, em todas as unidades, sem exceção. É pertinente pontuar que o aluno é colocado em situações de escrita a todo o momento, principalmente na atividade de Processo de produção de texto. Por fim, a oralidade tem um espaço menor no interior das unidades, pois acaba sendo desenvolvida um pouco em cada atividade, não apresentando em espaço específico para ela; ainda que sejam realizados exercícios de dramatização, leitura expressiva, teatro, entre outros, são atividades eventuais.

As autoras Beatriz Marcondes, Lenira Buscato e Paula Parisi organizaram o livro didático Português: dialogando com textos (MARCONDES; BUSCATO; PAURI, 2006), 5 a série, em sete unidades temáticas, estruturadas em torno de sete atividades, regularmente trabalhadas em todas as unidades: Motivações, Descobertas, Reinvenção, PapoFirme, Lendo Mais, Realimentação e Roda de Leitura, variando, em alguns momentos, a ordem de trabalho com cada uma delas. Essa organização deixa transparecer a seleção dos objetos de ensino, que são leitura, oralidade, gramática e escrita. Tais objetos são trabalhados com base em atividades e a partir de dois grandes eixos: texto e gramática. A ênfase dada à leitura se revela em função do grande número de atividades que envolvem esse objeto, seja na Motivação inicial, no texto central da unidade (Descobertas), em Lendo mais, seja na Roda de Leitura ou Realimentação; há uma condução do aluno para que, aos poucos, o gosto pela leitura seja internalizado, pelo fato de ser disponibilizado um conjunto de textos temáticos o qual possibilita conhecer diferentes aspectos de um mesmo tema. Além disso, em grande parte das vezes, a leitura é direcionada justamente para que o aluno possa construir o seu acervo de leituras e, de forma gradativa, dialogar com diferentes textos.

Ocupando a leitura tal posição, às demais atividades é reservado um lugar secundário, com atividades específicas para cada uma delas. Mas, dentre esses outros objetos, oralidade, escrita e gramática, a oralidade e a escrita recebem um tratamento diferenciado, por meio das atividades de Reinvenção (proposta de produção de texto escrito) e Papo-Firme (proposta de produção de texto oral). Esses objetos são trabalhados em um conjunto de aulas, as quais extrapolam, muitas vezes, o tempo de uma aula e o espaço de sala de aula. Também, para que o trabalho de produção textual (escrita e oral) possa ser desenvolvido de forma a atender aos objetivos, as autoras apresentam diferentes 
sugestões de atividades e informações a fim de que o aluno possa enriquecer as atividades. A gramática, por sua vez, mantém seu espaço reservado na atividade Descobertas - indo e vindo e Realimentação, justamente para que o aluno possa trabalhar com os elementos gramaticais a partir do estudo textual.

Os autores Carlos Emílio Faraco, Francisco Marto de Moura e José Hamilton Maruxo Junior organizaram o livro didático Língua Portuguesa: linguagem e interação (FARACO; MOURA; MARUXO JUNIOR, 2009), $6^{\circ}$ ano, em três grandes projetos temáticos, denominados de $\mathrm{O}$ meu álbum de família, O meu livro de histórias e Jornal mural. Cada um deles está dividido regularmente em quatro unidades, também temáticas, ligadas ao tema do projeto. As unidades apresentam um conjunto fixo e invariável de atividades para o estudo da temática proposta e, igualmente, para o desenvolvimento dos objetos de ensino: texto, para entender o texto, as palavras no contexto, gramática textual, ortografia e pontuação, linguagem oral, reflexão sobre a língua, prática de linguagem, produção escrita e para ir mais longe. Essa organização permite depreender que a concepção de unidade, assumida pelos autores, é a de um conjunto de atividades direcionadas a uma temática a qual, por sua vez, dialoga com outras unidades também temáticas, agrupadas a serviço do desenvolvimento de um projeto temático comum, que permeia as quatro unidades. A unidade temática é concluída quando são vencidas todas as atividades relacionadas aos objetos de ensino selecionados e articulados com uma determinada temática.

A organização das unidades deixa transparecer a seleção dos objetos de ensino leitura, oralidade, gramática e escrita, que são trabalhados com base em atividades e a partir de dois grandes eixos: texto e gramática. $O$ trabalho envolvendo a escrita ocupa lugar de maior destaque na obra, justamente por proporcionar diferentes atividades para a exploração desse objeto de ensino, centradas, principalmente, na atividade de Produção escrita; além disso, esse objeto de ensino perpassa todas as demais atividades, pois, a todo o momento, o aluno é solicitado a escrever/reescrever/registrar/copiar, em seu caderno, as respostas das questões propostas ou é pedido que ele elabore um esboço das questões antes de serem apresentadas à turma e ao professor.

Em um segundo plano, nesse manual, está a gramática, priorizada, em especial, nas atividades de Gramática textual, Ortografia e pontuação, Reflexão sobre a língua e Prática de linguagem. Embora esse objeto de ensino seja contemplado em um número 
maior de atividades, ainda assim ocupa um lugar secundário nesse livro didático.

A oralidade e a leitura, do mesmo modo, ocupam um lugar secundário: a oralidade é explorada de forma direta na atividade Linguagem oral; entretanto, em vários momentos da execução de outras atividades (Para ir mais longe, As palavras no contexto, Produção escrita) ela se faz presente. Isso ocorre sempre que os alunos são solicitados a apresentar aos colegas as produções realizadas; já a leitura está presente na leitura dos textos propostos, nas indicações de leituras que poderão ser realizadas pelo aluno (indicação de livros, sites, músicas, etc.) e nas atividades voltadas ao texto (Para entender o texto, As palavras no contexto). O objeto de ensino leitura não vem denominado na atividade proposta, como ocorre com os demais objetos de ensino, mas as marcas deixadas nas atividades (leia, releia, dentre outros procedimentos) sinalizam a preocupação dos autores em mobilizarem o trabalho relacionado ao ler.

A análise realizada, nos cinco livros didáticos inscritos no PNLD e publicados a partir de 1999, indicia que existe uma estrutura mínima comum que perpassa todos os manuais, marcada por dois eixos centrais, os quais sustentam as unidades: texto, com os exercícios sobre o texto; gramática, com os exercícios gramaticais. Ainda, percebe-se que há uma manutenção da tradição no momento em que todos os manuais iniciam com um texto e, a partir do texto, são desenvolvidas as atividades de acordo com os objetos de ensino selecionados.

\section{Atribuição de sentidos}

A estrutura das unidades nos conduz à análise dos objetos de ensino leitura, gramática, escrita e oralidade, enfocados pelos diferentes autores, nos distintos manuais descritos. Pelos elementos esboçados nos itens anteriores, antecipei que existe uma estrutura mínima comum, marcada por dois eixos centrais, os quais sustentam as unidades, dando continuidade a uma tradição do ensino de língua portuguesa: texto, com os exercícios relativos ao texto; gramática, com os exercícios gramaticais. Todas as unidades iniciam com um texto e, com base nesse, desenvolvem-se as atividades de acordo com os objetos de ensino selecionados.

Tais objetos de ensino recebem diferentes acentos em cada manual, em função das seleções/escolhas realizadas por cada autor, marcando, dessa forma, diferentes posições axiológicas (BAKHTIN, 2006) sobre o ensino de língua portuguesa, uma vez que 
alguns são priorizados, outros são abordados de forma secundária e/ou são desconsiderados em algumas coleções.

Conforme já mencionado, um objeto de ensino é priorizado nos respectivos manuais, sendo os demais abordados de forma secundária. Se uma hierarquia se estabelece, entre objeto priorizado e os demais, o que ainda se pode notar é que, mesmo os objetos secundários não sendo tratados da mesma forma, há também uma hierarquia de importância entre eles. Isso ocorre por não serem tratados e, consequentemente, trabalhados, com a mesma intensidade. Ademais, nem sempre os quatro objetos de ensino estão presentes nos livros didáticos; às vezes, existem apenas três, o que nos leva a perceber que, em determinados livros, um deles é descartado, talvez por ser considerado de menor importância social ou como um objeto de conhecimento prévio suficiente, por parte do aluno, no ensino de língua.

Observando os objetos de ensino priorizados antes do PNLD, é perceptível a escrita como objeto central, nas décadas de 1960 e 1980, o que, de certa forma, pode causar um certo estranhamento em virtude de ser ainda um período muito marcado pelo estudo da gramática tradicional, como ocorre, por exemplo, na década de 1970, em que a gramática se mantinha como objeto que recebia maior ênfase. $O$ que se percebe é que alguns autores começavam, embora de forma ainda muito inicial, a eleger um outro objeto de ensino, como é o caso da escrita, na tentativa de trabalhar mais com atividades que girassem em torno do texto e do ensino da língua do que o ensino sobre a língua (GERALDI, 1984). Certamente, isso se deu em função da ação de fatores internos e externos a interferir no desenvolvimento da disciplina escolar língua portuguesa.

É interessante observar, do mesmo modo, que a gramática, mesmo ocupando um lugar secundário, nas décadas de 1960 e 1980, encontra-se em primeiro lugar dentre os demais objetos secundários, o que me leva a entender que continuava a ser considerada como de grande importância no ensino de língua portuguesa, ensinada a partir da exposição de conceitos e de exemplos, como forma de ensinar a língua portuguesa padrão culta, marcando, assim, seu espaço nas diferentes unidades. A leitura, embora esteja presente nas três décadas, é tratada sempre como objeto secundário. Com relação à oralidade, é possível notar que os acentos também são diferentes no decorrer das três décadas; olhar para a oralidade, na década de 1970, é vê-la quase sem ênfase; entretanto, há algumas atividades que possibilitam o desenvolvimento desse objeto. Situação 
diferente é o que se pode encontrar nas décadas de 1960 e 1980, quando, além de serem encontrados apenas dois objetos de ensino secundários selecionados, dentre eles a oralidade não é incluída, ou seja, é desconsiderada, pois não são localizados registros de atividades que mobilizem o trabalho com esse objeto.

A partir da vigência do PNLD, foi possível detectar uma manutenção da escrita e a entrada da leitura como objetos de ensino priorizados no ensino de língua portuguesa: quando a leitura é priorizada, a escrita é trabalhada como objeto secundário; se a escrita é priorizada, é a leitura que se apresenta como objeto secundário. De certa forma, ao serem priorizados esses dois objetos de ensino, é explicitado que há uma preocupação, por parte dos autores, de atenderem ao que os PCNs propõem para o tratamento desses objetos, ou seja, "atualmente, exigem-se níveis de leitura e de escrita diferentes dos que satisfizeram as demandas sociais até há bem pouco tempo - e tudo indica que essa exigência tende a ser crescente" (BRASIL, 1998, p. 23), já que, até a década de 1980, o ensino ainda estava voltado para o ensino gramatical, lugar frequentemente ocupado pela gramática tradicional, embora alguns autores já sinalizassem para o trabalho relacionado ao texto. De certo modo, o trabalho com a leitura e escrita tornou-se contínuo de um PNLD para outro (e tudo indica que essa exigência tende a ser crescente), em virtude de serem priorizados esses dois objetos de ensino até 2011, período analisado nesta pesquisa.

Ao ser priorizada ora a leitura ora a escrita, os demais objetos de ensino (gramática e oralidade) passam a ser considerados como secundários: a gramática é sempre desenvolvida nos diferentes períodos, com um trabalho abarcando, frequentemente, a apresentação de conceitos, exemplificações e a realização de atividades geralmente metalinguísticas. O que vai se acentuando, nas obras descritas, ao longo do PNLD, é o tratamento atribuído à gramática: em alguns momentos, ela poderia ser banida dos manuais, conforme Luft e Correa (1996); em outros, há a preocupação em proporcionar a construção dos conhecimentos gramaticais a partir de exemplos e de comparações (CEREJA; MAGALHÃES, 1998; PRATES, 2005); e, em alguns, é observado que os elementos gramaticais permeiam as diferentes atividades, não ficando restritos apenas a uma atividade (FARACO; MOURA; MARUXO JUNIOR, 2009; MARCONDES; BUSCATO; PAURI, 2006). Tal fato possibilita que a gramática seja empregada "instrumento de apoio para a discussão dos aspectos da língua" (BRASIL, 1998, p. 28). É possível verificar que o atendimento 
aos PCNs, em relação à gramática, vem ocorrendo ao longo das edições do PNLD, ou seja, o tratamento de Luft e Correa (1996) é o de banir a gramática dos manuais; já Marcondes, Buscato e Lauri (2006) e Faraco, Moura e Maruxo Junior (2009) procuram utilizar a gramática para a discussão dos aspectos da língua, isto é, conforme as coleções vão sendo lançadas, há um entendimento maior, por parte dos autores, de saber como abordar o aspecto gramatical em suas obras. Além disso, como o PNLD se coloca como instrumento regulador e avaliador dos livros didáticos, os autores se veem obrigados a atender às exigências desse Programa para terem suas coleções aprovadas.

O que não se pode negar é que os PNC influenciaram diretamente nesse novo tratamento concedido à gramática, em função de o documento oficial priorizar o texto como unidade básica do ensino e não mais a gramática. No entanto, anterior aos PCNs, a ciência linguística, a partir dos anos de 1970/1980, também já sinalizava para novas concepções de linguagem e de língua, novos conteúdos e uma nova metodologia para a disciplina de português (SOARES, 2002).

A oralidade, por sua vez, é sempre vista como um objeto secundário em Luft e Correa (1996) Cereja e Magalhães (1998), Marcondes, Buscato e Lauri (2006) e Faraco, Moura e Maruxo Junior (2009), sendo abordada, geralmente, em atividades eventuais, fato que não condiz com a importância atribuída a esse objeto, no contexto dos PCNs, em que "ensinar o aluno a produzir textos orais significa, sobretudo, organizar situações que possibilitem o desenvolvimento de procedimentos de preparação prévia e de monitoramento simultâneo da fala" (BRASIL, 1998, p. 74). De certa forma, a oralidade

[...] precisa lutar pelo seu espaço como objeto de ensino legítimo nas aulas de língua portuguesa", em decorrência de a "escrita ser tomada como um objeto de ensino naturalizado, com espaço há muito sedimentado, não sendo discutida a sua permanência na esfera escolar" (WINCH, 2014, p. 186).

Na realidade, o trabalho com a oralidade precisa de novos olhares, de forma a ser reconhecida como objeto priorizado no ensino de língua portuguesa, assim como é reconhecida a escrita (WINCH, 2014). Infelizmente, ainda são encontrados manuais, como é o caso de Prates (2005), em que a oralidade é desconsiderada como objeto de ensino.

Cada objeto de ensino, enquanto signo (leitura, oralidade, gramática e escrita), na visão bakhtiniana, refrata de forma desigual no interior das unidades das coleções a partir 
da posição axiológica assinada por cada autor. Pensando a partir do que propõe Faraco (2003), retomando Bakhtin, a refração é uma condição necessária do signo, porque refratar significa que, com os signos, nós não somente descrevemos o mundo, mas "construímos diversas interpretações (refrações) desse mundo" (FARACO, 2003, p. 50). Logo, como resultado das diferentes práticas, diferentes interpretações ocorridas, nas diversas esferas, os signos vão recebendo novos sentidos e novas valorações. É o que ocorre com os objetos de ensino que compõem a estrutura das unidades dos diferentes manuais. No seu processo de estruturação, esses objetos refratam de forma diferente, pois, à medida que a esfera escolar se desenvolve e fica mais complexa, esses objetos ganham novos sentidos, diferenciando-se uns dos outros; eles aparecem ou desaparecem em função das condições sócio-históricas (BAKHTIN, 2006).

Nesse processo de ênfases diferenciadas, em relação aos objetos de ensino, a gramática, de uma posição privilegiada no ensino de língua portuguesa, no chamado ensino tradicional, passa, conforme análise nos livros, à posição secundária. Todavia, ela nunca é desconsiderada como objeto de ensino. Já a oralidade, nunca chegou a ser tomada como objeto de ensino priorizado e, em alguns livros, sequer foi considerada como objeto secundário.

Outro aspecto que merece destaque, no tratamento dos objetos de ensino, diz respeito à forma diferenciada de identificação das atividades didáticas no interior das unidades dos distintos manuais analisados, passando de uma identificação direta para se referir ao objeto de ensino enfocado para uma nomeação de "difícil" identificação do objeto de ensino em questão. Em Mesquita e Martos (1979), a nomeação de grande parte das atividades remete, diretamente, ao objeto de ensino: estudo do texto, família das palavras/observando a linguagem, aprendendo a pensar (leitura); linguagem oral e comunicação (oralidade); criatividade, pesquisa, escrevendo corretamente (escrita); conhecimentos linguísticos (gramática). De forma muito semelhante, ocorre no manual de Luft e Correa (1996): interpretação textual, leitura suplementar (leitura); atividade oral (oralidade); sala de redação (escrita); gramática e treino ortográfico (gramática). Já em Prates (2005), a partir da identificação da atividade, é possível perceber mais de um objeto de ensino sendo mencionado, ocorrendo, também, repetições de objetos citados em diferentes atividades das unidades temáticas: Visão crítica: fala, leitura e escrita (oralidade/leitura/escrita); A palavra escrita e falada (escrita/oralidade). 
Situação muito diferente ocorre com as nomeações das atividades em Marcondes, Buscato e Lauri (2006), uma vez que não possibilitam o reconhecimento dos objetos de ensino priorizados: motivações, descobertas, reinvenção, papo-firme e realimentação. Foi por intermédio do percurso descritivo de cada unidade temática que fui desvendando os objetos de ensino trabalhados pelas autoras: Reinvenção (escrita); Papo-firme (oralidade); Motivação, Descobertas, e Realimentação (Leitura); Descobertas: indo e vindo e Realimentação (gramática). Como entender, então, esse novo processo de nomear as atividades? Não tenho uma resposta, mas sinalizo algumas possibilidades de entendimento/compreensão sobre essas formas de denominação: primeiro, ao deixar de nomear, diretamente, os objetos de ensino, nas atividades, é permitido que ocorra um extravasamento de um objeto para outro, pois não há a demarcação de fronteiras de onde começa ou termina o trabalho, ocorrendo, muito provavelmente, um diálogo entre eles (leitura/oralidade; escrita/gramática, por exemplo); segundo, esse procedimento pode servir como uma estratégia pedagógica para se aproximar do atual aluno da escola básica, no momento em que usa termos mais convidativos, chamativos (Descobertas, Papo-firme, reinvenção), aproximando-se mais da linguagem do aluno que temos hoje. De certa forma, essa nova maneira de denominar as atividades que constituem as unidades dos livros didáticos parece ser recorrente a partir da implantação dos PCNs e vem se acentuando ao longo dos tempos.

Os aspectos considerados fornecem subsídios para dialogar, nesse momento, com as permanências, os deslocamentos e as alterações ocorridas na apresentação dos objetos de ensino das unidades didáticas de livros da disciplina escolar língua portuguesa. Esse diálogo é guiado pela compreensão/interpretação bakhtiniana, por estarmos diante de textos que não são coisas mudas, mas a expressão de, pelo menos, dois sujeitos: o que analisa e o analisado (BAKHTIN, 1997, p. 404), porque

[...] compreender é cotejar com outros textos e pensar num contexto novo (no meu contexto, no contexto contemporâneo, no contexto futuro). Além disso, o texto só vive em contato com outro texto (contexto) e é somente em seu ponto de contato é que surge a luz que aclara para trás e para frente, fazendo que o texto participe de um diálogo (BAKHTIN, 1997, p. 404).

É no contato com outros textos que vamos construindo um novo texto, na tentativa 
de responder a mais um aspecto direcionado às unidades didáticas.

Ao me debruçar sobre as permanências, alguns elementos chamam a atenção: primeiro, a unidade é sempre iniciada por um texto, seguido, posteriormente, pela gramática, nunca ocorrendo o contrário; dessa estrutura, são encontrados os dois eixos centrais, mantendo a tradição envolvendo texto, com exercícios relativos ao texto e à gramática, com os exercícios gramaticais, o que caracteriza um processo permanente de homogeneização da estrutura em que se assentam as unidades. A partir desses dois elementos da tradição, os autores dividem as unidades didáticas em partes as quais, geralmente, repetem-se para ocorrer o trabalho didático, sendo que essas partes passam a integrar uma sequência de atividades, podendo ser uma sequência fixa ou variável de atividades, e essas atividades sendo invariáveis e, em alguns casos, variáveis.

O segundo elemento está relacionado à leitura e à escrita que, com o passar das décadas e dos PNLD, consolidam-se como objetos priorizados a partir dos anos 80 , ou seja, além de a escrita manter-se como objeto principal, a leitura também passa a ocupar um lugar de ênfase nas unidades. Já a oralidade, como elemento secundário, é o quarto elemento que chama a atenção como permanente nas unidades; é perceptível que esse objeto de ensino não consegue ocupar lugar priorizado dentre os demais objetos, mantendo-se com status de secundário e/ou desconsiderado em todo o período investigado. Do conjunto de livros analisados, o que se pode notar é uma predominância de um trabalho nas unidades em que elas têm um fechamento em si mesmas, independente do período antes ou na vigência do PNLD e do fato de serem unidades temáticas ou não.

Quanto aos deslocamentos, percebo, inicialmente, que os objetos de ensino vão se deslocando em função da forma diferenciada de conceber o ensino de língua materna (com base em concepções diferenciadas de linguagem e de língua) ao longo do período de tempo analisado e, consequentemente, da importância que essa nova concepção atribui aos diferentes objetos de ensino. É o caso, por exemplo, da gramática, que deixa de ocupar um lugar priorizado dentro das unidades e passa a ser tomada como secundária. Esse deslocamento, entretanto, inicia-se vagarosamente, nos anos de 1960, firmando-se em períodos posteriores, com a publicação dos PNCs. O lugar vago, deixado pela gramática, é ocupado ora pela leitura, ora pela escrita enquanto objetos priorizados.

Ao considerar as alterações ocorridas nas coleções, noto que, com a publicação 
dos PCNs e das determinações fixadas a partir do PNLD, acentua-se o efeito de homogeneização nos livros didáticos e nas unidades, processo esse já iniciado nos anos 60 e 70 (BATISTA, 2001). Os livros didáticos, antes da vigência do PNLD, são um exemplo de um relativo escape dessa homogeneização, em termos da produção e de organização em unidades: parece ocorrer um trabalho mais autoral, nas mãos dos seus elaboradores, se nos detivermos, por exemplo, em Guimarães (1960), Mesquita e Martos(1979) e Sargentim (1981).

Por fim, cabe pontuar que os resultados dessa investigação dizem respeito ao conjunto de livros analisados nesse artigo; se outras coleções forem selecionadas, outros resultados, provavelmente, serão encontrados.

\section{Palavras finais}

Ao final dessa discussão, é possível destacar alguns aspectos que sinalizam a relevância do trabalho desenvolvido, pois, como participante do diálogo envolvendo os objetos de ensino dos livros didáticos de português do Ensino Fundamental II, de distintos períodos - décadas de 1960, 1970 e 1980, 1997, 2010 - (PNLD 1999, 2002, 2005, 2008, 2011), fui marcando minha posição axiológica por meio de uma atitude responsiva, a qual, aos poucos, foi sendo construída a partir do interesse em investigar outros aspectos relacionados ao livro didático. Ao construir meu dizer, outros enunciados precedentes foram sendo mobilizados, em decorrência desse dizer ser parte integrante de uma "discussão cultural em grande escala: ele responde ao já-dito, refuta, confirma, antecipa respostas e objeções pontuais" (BAKHTIN, 2006, p. 323).

Além disso, o conhecimento a respeito dos objetos de ensino não só atende às exigências desta pesquisa como também amplia o conhecimento da própria trajetória do ensino de língua portuguesa com base nos objetos priorizados: o ensino vai se reconfigurando a partir das posturas axiológicas em relação ao que se prevê como prioridade para o ensino de língua portuguesa. Os livros didáticos são um sinalizador dos processos de permanência, alteração e deslocamentos no ensino de língua, ainda mais quando há um documento oficial norteador/balizador, como os PCNs, e um instrumento regulador, como o PNLD.

A partir dos resultados deste artigo, acredito que outras pesquisas possam surgir, as quais estudem, talvez, coleções didáticas existentes e que não foram submetidas ao 
PNLD, mas que circulam na esfera escolar, a fim de observar quais os objetos de ensino priorizados. Da mesma forma, novas pesquisas poderão investigar outras coleções das mesmas décadas abordadas nesse trabalho, como uma maneira de confirmar esses dados ou, ainda, analisar coleções de décadas posteriores para conhecer como se apresentam os objetos de ensino nesses manuais. Certamente, a ampliação desses estudos, envolvendo o passado e o presente do ensino de língua portuguesa, poderá auxiliar na formação de futuros professores dessa disciplina.

\section{Referências}

BAKHTIN, Mikhail Mikhailovitch. Observações sobre a epistemologia das ciênciashumanas. In: BAKHTIN, Mikhail Mikhailovitch. Estética da criação verbal. Tradução de Paulo Bezerra. São Paulo: Martins Fontes, 1997. p. 401-414.

BAKHTIN, Mikhail Mikhailovitch. Os gêneros do discurso. In: BAKHTIN, Mikhail Mikhailovitch. Estética da criação verbal. Tradução de Paulo Bezerra. 4. ed. São Paulo: Martins Fontes, 2006. p. 261-306.

BAKHTIN, Mikhail Mikhailovitch. Reformulação do livro sobre Dostoiévski. In: BAKHTIN, Mikhail Mikhailovitch. Estética da criação verbal. Tradução de Paulo Bezerra. São Paulo: Martins Fontes, 2006. p. 338-357.

BATISTA, Antônio Augusto Gomes. O conceito de "livros didáticos". In: BATISTA, Antonio Augusto Gomes; GALVÃO, Ana Maria de Oliveira (org.). Livros escolares de leitura no Brasil: elementos para uma história. Campinas, SP: Mercado de Letras, 2009. p. 4173.

BATISTA, Antônio Augusto Gomes. Recomendações para uma política pública de livros didáticos. Brasília: Ministério da Educação, Secretaria de Educação Fundamental, 2001.

BATISTA, Antônio Augusto Gomes. Um objeto variável e instável: textos, impressos e livros didáticos. In: ABREU, Márcia (org.). Leitura, história e história da leitura. Campinas: Mercado de Letras, 1999. p. 529-575.

BENTES, Anna Christina. Linguagem oral no espaço escolar: rediscutindo o lugar das práticas e dos gêneros orais na escola. In: RANGEL, Egon de Oliveira; ROJO, Roxane Helena Rodrigues (org.). Língua portuguesa: ensino fundamental. Brasília: Ministério da Educação, Secretaria da Educação Básica, 2010. (Coleção Explorando o Ensino, v. 19).

BRASIL. Ministério da Educação. Parâmetros curriculares nacionais: introdução. Brasília: MEC, SEF, 1998.

BUNZEN, Clécio dos Santos. Construção de um objeto de investigação complexo: o livro didático de língua portuguesa. Estudos Linguísticos, São Paulo, n. 34, p. 557-562, 2005a. 
BUNZEN, Clécio dos Santos. Livro didático de Língua Portuguesa: um gênero do discurso. 2005. 168 f. Dissertação (Mestrado em Ensino/Aprendizagem de Língua Materna) - Universidade Estadual de Campinas, São Paulo, 2005b.

CEREJA, William Roberto; MAGALHÃES, Thereza Cochar. Português: linguagens. $5^{a}$ série do ensino fundamental. São Paulo: Atual, 1998.

FARACO, Carlos Alberto. Linguagem e diálogo: as ideias linguísticas do Círculo de Bakhtin. Curitiba, Paraná: Criar, 2003.

FARACO, Carlos Emílio; MOURA, Francisco Marto; MARUXO JUNIOR, José Hamilton. Língua portuguesa: linguagem e Interação: $6^{\circ}$ ano do ensino fundamental. São Paulo: Ática, 2009.

GERALDI, João Wanderley. Concepções de linguagem e ensino de Português. In: GERALDI, João Wanderley (org.). O texto na sala de aula: leitura \& produção. 2. ed. Cascavel: ASSOESTE, 1984. p. 39-46.

GUIMARÃES, Magda Soares. Português através de textos: $1^{a}$ série ginasial. Belo Horizonte: Bernardo Alvares, 1960.

LAURIA, Maria Paula Parisi. Livros didáticos de português: entre as concepções de ensino, os trilhos da lei e as sendas do texto. 2004. $316 \mathrm{f}$. Tese (Doutorado em Linguagem e Educação) - Universidade de São Paulo, São Paulo, 2004.

LUFT, Celso Pedro; CORREA, Maria Helena. A palavra é sua: $5^{\text {a }}$ série do ensino de primeiro grau. São Paulo: Scipione, 1996.

MARCONDES, Beatriz; BUSCATO, Lenira Aparecida; LAURI, Maria Paula Parisi. Português: dialogando com textos: $5^{a}$ série do ensino fundamental. 2. ed. Curitiba: Positivo, 2006.

MESQUITA, Roberto Melo; MARTOS, Cloder Rivas. Comunicação e expressão: processo auto-instrutivo: $6^{\mathrm{a}}$ série do ensino de primeiro grau. São Paulo: Saraiva, 1979.

PRATES, Marilda. Encontro e desencontro em língua portuguesa: reflexão \& ação: $5^{a}$ série do ensino fundamental. São Paulo: Moderna, 2005.

SARGENTIM, Hermínio G. Montagem e desmontagem de textos: $5^{a}$ série do ensino de primeiro grau. Brasília: Instituto Brasileiro de Edições Pedagógicas do Ministério da Educação, 1981.

SOARES, Magda Becker. Português na escola: história de uma disciplina curricular. In: BAGNO, M. (org.). Linguística da norma. São Paulo: Loyola, 2002. p. 155-177.

SOARES, Magda Becker. Um olhar sobre o livro didático. Presença Pedagógica, Belo Horizonte, v. 2, n. 12, p. 52-64, nov./dez. 1996.

WINCH, Paula Gaida. Oralidade e livro didático: uma possível reconfiguração no ensino de língua portuguesa. 2014. 246 f. Tese (Doutorado em Letras) - Universidade Federal 
Leitura, oralidade, escrita e gramática: alterações, deslocamentos e permanências nas unidades didáticas dos livros didáticos de Português do Ensino Fundamental II

de Santa Maria, Santa Maria, 2014.

Submetido em: 28 fev. 2020.

Aceito em: 15 set. 2020. 